\title{
The Improvement of the Comfort of Public Spaces as a Local Initiative in Coping with Climate Change
}

\author{
Milena Vukmirovic*(D), Suzana Gavrilovic and Dalibor Stojanovic \\ Faculty of Forestry, the University of Belgrade, Belgrade 11000, Serbia; suzana.gavrilovic@sfb.bg.ac.rs (S.G.); \\ student.daliborstojanovic1853023@sfb.bg.ac.rs (D.S.) \\ * Correspondence: milena.vukmirovic@sfb.bg.ac.rs; Tel.: +381-11-305-3913
}

Received: 30 September 2019; Accepted: 8 November 2019; Published: 20 November 2019

check for updates

\begin{abstract}
Being the vital element of successful cities, public spaces play an important role in achieving sustainable development goals and in coping with climate change. The new urban agenda considers public spaces indispensable for sustaining the productivity of cities, social cohesion and inclusion, civic identity, and quality of life. Accordingly, there is no doubt about the importance of public spaces, while their quality is generated through the symbiosis of various elements. On the basis of normative theories of urban design, several public space design frameworks have been established in order to define what makes a good public place. Such a framework for public space quality evaluation is developed and tested at the Chair for Planning and Design in Landscape Architecture at the University of Belgrade-Faculty of Forestry. The framework covers six criteria which illuminate key aspects of public spaces: safety and security, accessibility, legibility, comfort, inspiration and sensitivity and liveability. In this research, special attention is paid to the criteria of comfort analysed on two scale levels in Belgrade, Serbia. In the past, Belgrade was affected by extreme weather events that caused serious and sometimes disastrous consequences. The most pronounced challenges among them are heat waves in summer that, due to the shortage of vegetation combined with the proliferation of tarmac and concrete surfaces and reduced air ventilation, particularly threaten the densely populated central municipalities of Stari Grad, Savski Venac and Vracar. The first scale level covers the analysis of the public space network and the degree of establishment of green infrastructure in Lower Dorcol quartier, which is located in the Municipality of Stari Grad, using quantitative and qualitative indicators and GIS (Geographic Information System) digital tools. The aim of this study is to observe the actual state of the public space network and to define a future scenario of its development in line with climate change challenges. Jevrejska Street, as an element of the above-mentioned public space network, is the subject of the next phase of the research. The study on this scale level will cover qualitative and quantitative analysis of public space elements such as paving, urban equipment, greenery, lighting, water facilities, etc. Next to that, by using the ENVI Met platform, the actual and proposed improvement of the street will be explored. The final part of this research will include a discussion about the research methodology used in order to improve the public space design process and to point out the need for the careful consideration of comfort as an important aspect of good public space.
\end{abstract}

Keywords: public space; comfort; climate change; ENVI Met; Belgrade

We know more about the comfort and preferred habitats of elephants than we know about what makes people thrive in cities. [1]

\section{Introduction}

It can be said that we are living in the era labelled as Anthropocene ("In 2016 or thereabouts, the International Commission on Stratigraphy—-the scientific body that maintains the official Geologic 
Time Scale-will consider a proposal to formalize a definition of this term. It's a decision that has both semantic and scientific implications and may have legal implications as well" [2,3], "the era in which human influence is the dominant source of change in the ecosystem" [4]. Considering the impacts on the planet, characterized by this epoque, Ellis [5] has noted several issues such as fire, intensive hunting and agriculture, accelerated into rapid climate change, widespread pollution, plastic accumulation, species invasions, and the mass extinction of species that contributed to the changes that have left a permanent mark in the geological record of the rocks. From this perspective, some authors consider the Anthropocene as a source that could be used as "a call to action for environmental sustainability and responsibility" $[2,3,6]$. As Stephen Hawking said, since we have not yet "established self-sustaining colonies in space, ... we have to be very careful in this period" [7].

Climate change is recognized as among the global megatrends (the exploratory analysis summarized 11 global megatrends (GMTs) grouped into five clusters-social, technological, economic, environmental and governance [8]) that challenge the future. Therefore, we are the witnesses of global warming taking hold, winters becoming wetter, summers drier and extreme rainfall more frequent. The consequences of urbanization and climate change are converging in threatening ways. Based on current national government predictions, global warming will reach 1.5 degrees Celsius between 2030 and 2052, and approximately 3 degrees Celsius in 2100, which will have a devastating impact on cities. In urban environments, climate change means an increase in warmth in cities and more frequent flooding and waterlogging, while dry periods occur more often and last longer [9]. As Hawking said, "most of the threats we face come from the progress we have made in science and technology, but we do not have to stop making progress, or reverse it - we have to recognize the dangers and control them" [7].

Cities are major contributors to climate change, but at the same time, urban areas are also among the most vulnerable places in the world. Although they cover less than 2 per cent of the total Earth's surface, "urban areas account for 71 to 76 per cent of the world's carbon dioxide from global final energy use and a significant portion of total greenhouse gas emissions" [10]. Directly or indirectly, climate change has a negative impact on urban infrastructure and worsens the access to basic urban services and quality of life in cities, while the poorest population stands out as the most vulnerable group.

The alarming situation forced cities to join the frontline of climate action and to lead the way to support the transition to a low carbon economy, which means that cities acted first and national governments followed. The reason for this is seen in the responsibility for the daily lives of city residents that helped "many officials and mayors to understand that providing a climate-safe future promises multiple benefits such as a cleaner air, sustainable jobs and energy security" [11]. Their initiatives are focused on forming networks or urban-specific actions such as C40, the Covenant of Mayors for Climate and Energy and Mayors Adapt, in which they act together in order to foster local-level activities on adaptation and mitigation, and achieve globally measured goals such as the reduction of the risks associated with a global warming of 1.5 and 2 degrees Celsius above pre-industrial levels [12].

Urban and landscape design can have a major impact on climate change. Being a special element of urban and landscape design, urban open public spaces play an important role in reducing high temperatures, but also in overcoming the impacts of climate change [13]. One of the actions is seen in "boosting green infrastructure, that does not only lead to increased resilience of the urban area, but is likely to also have numerous co-benefits, such as improved air quality, better health, improved biodiversity and enhanced overall quality of life for citizens" [14]. Such interventions in open public space could also be considered as the improvement of its comfort [15], seen as a "positive emotional reaction to external surroundings in different situations, including physical, social and psychological reactions", while "the feeling and degree of comfort is dependent on the surroundings, the situation and the individual" [16].

Considering all the above, this paper will analyse the potential of the open public space comfort improvement by introducing new elements of green infrastructure in order to meet the challenges of climate change. Special attention is given to the analysis of the continuity of the green infrastructure 
network, public space comfort analysed using the clustered indicators that cover greenery, urban equipment, water features and urban morphology, and the simulation of microclimate characteristics on the actual and proposed state of the particular public space in order to present new elements of the open public space design process developed at the University of Belgrade-Faculty of Forestry. They could be characterized as appropriate design tools that will be used in response to challenges such as increased intensities of heat waves, temperature thresholds and urban heat island (UHI) effects and to consider "new factors in the light of the volatile urban climate until the end of the century" [14].

\section{Open Public Space Comfort}

Open public space is a space available for all people [17] and "the vital ingredient of successful cities" [17]. In addition, these places are crucial in creating the sense of community, culture and social capital. Open public space is a place where people can perform various activities (movement, recreation, cultural activities, shopping, meeting new people, etc.) [18] and represents a gathering space, which includes squares, parks, streets and sidewalks [19]. They are an integral part of the urban landscape, which depends on buildings and structures in their immediate vicinity. Overall, open public spaces reflect the character and identity of a city, giving it meaning in an aesthetic, ecological and functional sense.

Being the key element in building inclusive, healthy, functional and productive cities, open public spaces could be observed as a strong tool in sustainable development by providing environmental, social, economic and health benefits to the city. Among the five allocated sustainable development goals (SDG) and objectives (see Figure 1), climate action (sustainable development goal No. 13) is also identified as a goal that can be influenced by open public spaces.

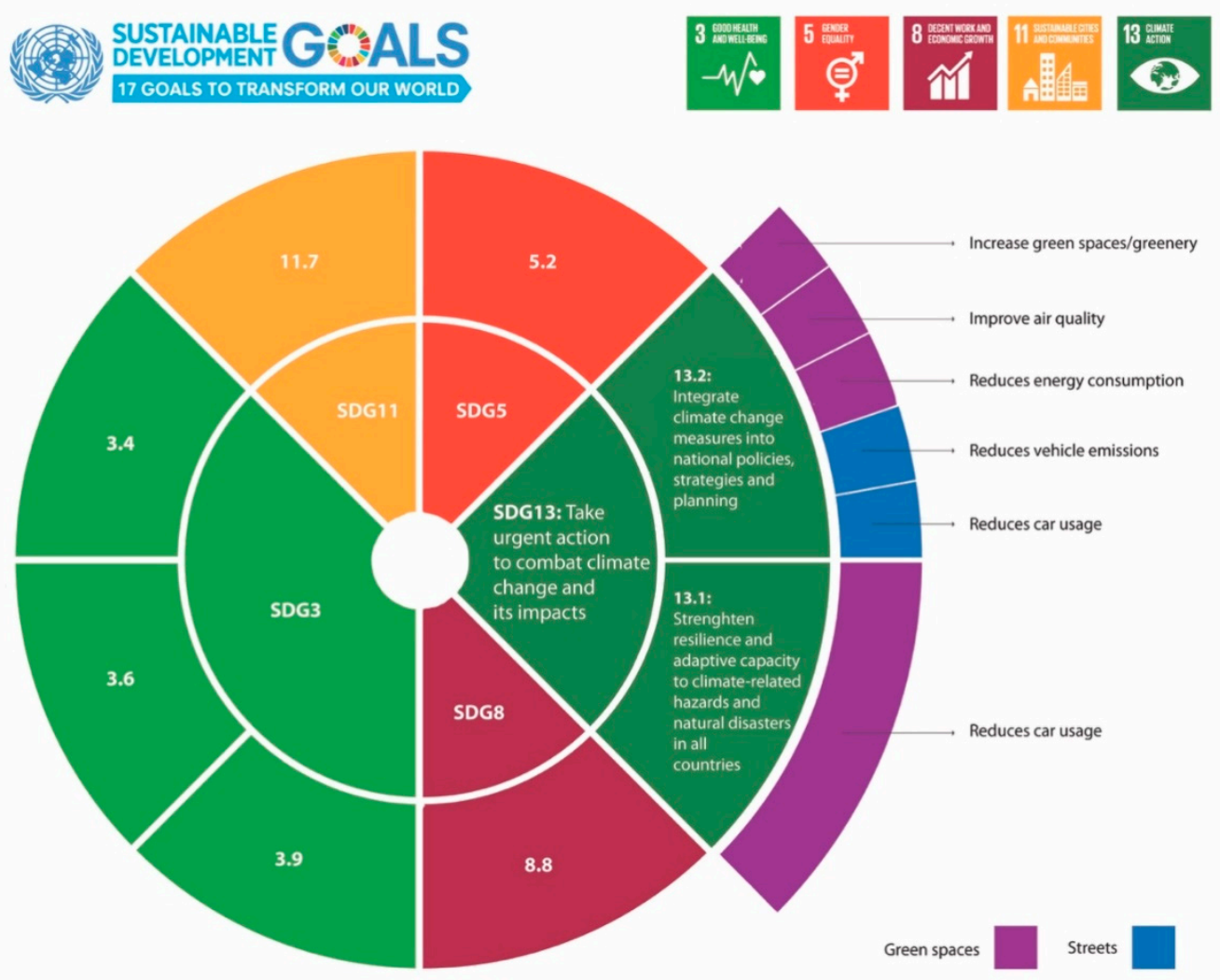

Figure 1. The potential of public spaces to contribute to several sustainable development goals.

Kristie [20] observes strengthening the resilience and adaptive capacity to climate-related hazards and natural disasters in all countries and the integration of climate change measures into national policies, strategies and planning to be the specific targets of the respective SDGs that can be 
achieved through public space development. More precisely, the benefits that could be achieved by improving open public spaces include the increase in green spaces/greenery, improvement of air quality, reduction of energy consumption, reduction of vehicle emissions and car usage and improvement of community cohesion.

In order to create good open public spaces, several frameworks [1,21-23] that cover criteria and requirements were defined on the basis of normative theories of urban design [21]. Comfort is recognized among the most important criteria. Considering the different impacts of the external environment, this complex criterion has different aspects, such as thermal comfort, visual comfort, acoustic comfort, tactile comfort, smell, air pollution and allergens, the ease to move and the feeling of security [16]. Their research has shown that the factors that influence the feeling of comfort when walking and spending time in open public spaces include feeling safe and secure, pavement conditions, lighting conditions, appealing surroundings, weather and traffic conditions.

In accordance with this, weather, or more broadly, climate is the most influential factor that determines the level of comfort, particularly the thermal comfort of the public. However, many open public space design processes are developed with little consideration of weather and climate factors such as air temperature, air humidity, wind speed and radiation fluxes [15]. The relationship between urban design parameters and user thermal comfort has been the subject of many studies [24-26] such as the influence of city design on wind flow and the reported effective role of ventilation in mitigating the high urban air temperatures and improving thermal comfort [27], and the effect of urban design strategies on the magnitude of received solar radiation and its influence on pedestrian thermal comfort [28]. However, recent studies [29] have focused on investigating the effects of particular elements of public space design and their influence on specific types of comfort, with the aim of defining urban design strategies that will be implemented in order to improve the level of comfort of public spaces.

The framework, which is being further developed at the University of Belgrade-Faculty of Forestry (the initial framework was designed in 2006 at the University of Belgrade-Faculty of Architecture by Prof. Dragana Bazik, MSc and Assist. Prof. Dr Milena Vukmirovic, following lectures and exercises on Bachelor Course Public Space Design. Further development of the Framework continued at the University of Belgrade-Faculty of Forestry, Department of Landscape Architecture and Horticulture by Assist. Prof. Dr Milena Vukmirovic on the Master course Open Public Space Design in order to define qualitative and quantitative indicators.) covers six open public space criteria-among which, a hierarchy was established: safety and security, accessibility, comfort, legibility, inspiration and attractiveness, and liveability [30]. The hierarchy is based on the following principle-in order to realize the higher rank criterion, it is necessary to achieve all the criteria that precede it. Comfort ranks third, which means that safety and accessibility are the only prerequisites.

Comfortable open public spaces must reduce potential risk, insecurity, bodily injury, unpleasant sensory influences, and negative aspects of the climate to a minimum, because it is not feasible without other specified intervention in open public spaces [1]. Although users have individual criteria and personal views on comfortable or less pleasant spaces, many will agree that the key to the successful public space design is respecting the needs and attitudes of people. According to Bazik [22], the aim of public space design is the establishment of liveable public spaces, which is only possible if the space is comfortable, attractive and inspiring.

\subsection{Open Public Space Comfort, Vegetation and Green Infrastructure}

Social and optional activities in open public spaces directly depend on the physical and psychological comfort of their users and are closely related to measures of the duration of stay and the intensity of use. Physical comfort refers to climate and microclimate conditions of the environment. Moreover, the importance of wind patterns upon local conditions was also established in studies conducted by White and Gehl $[22,31]$. Considering that, an open public space needs to provide better protection against unpleasant environmental conditions and weather, such as protection from 
excessive solar radiation during the summer. Accordingly, open public spaces need to be designed to make most of their space pleasant and thermally acceptable to all users [32].

Deliberately designed open public spaces with carefully planned and organized vegetation following the principles of green infrastructure could be considered an answer to many negative influences that may demean a sense of comfort in urban environments. For example, a prevalence of built-up areas and lack of green space leads to higher urban temperatures (the urban heat island effect). The large proportion of sealed surfaces also reduces natural drainage, which can lead to more severe urban floods during heavy rains. The project "Good Green is Golden" discusses the impact of green infrastructure in urban areas. Boer et al. [33] emphasise the advantages of urban vegetation such as the reduction and storage of emissions and protection from noise, solar radiation, stormy wind, flood and humidity. The above are just some of the positive effects that directly affect the impression of open public space users. Green infrastructure has the dominant influence on the microclimatic characteristics of open public spaces. High temperatures during summer make the users search for areas that are thermally acceptable to be used as an extract from excessive solar radiation or noise.

The concept of green infrastructure can be broadly defined as a strategically planned network of natural and semi-natural elements with other environmental features, which is designed and managed to deliver a wide range of ecosystem services [31]. In conditions of climate change, the concept of green infrastructure may be considered the most appropriate for flexible planning in urban landscapes [34]. Urban vegetation can affect the microclimate on the level of particular public spaces (parks, squares, streets or urban pockets) or the climate of the broader area such as the city district, if it is understood as an element of the green infrastructure system. This can be observed through three positive effects affecting thermal comfort: shading, relative humidity and wind protection. Vegetation in urban areas also contributes to the impression of comfort through the reduction of harmful sunlight, high temperatures, ventilation and relative air humidity. In terms of protection against the harmful influences, the effects of vegetation are important to provide noise reduction, decrease in atmospheric pollution and improve air quality, rainwater, protection from erosion due to wind and water [35].

In the context of climate change, especially considering the implications of increased temperature, heat waves and UHI effects in densely populated urban areas, comfort gains a new emphasis in the evaluation of public space quality. Therefore, the purpose of this research is reflected in the intention to improve the open public space design process, focusing on comfort criteria in order to emphasize the use of vegetation seen as the elements of green infrastructure and its careful and thoughtful use and inclusion in public space design proposals and interventions. A special aim is to point out the importance and necessity of vegetation and green infrastructure, both at the local level for the improvement of microclimate impacts and at a wider level, measured through mitigation of climate change.

\subsection{Public Space Comfort Clusters and Indicators}

The comfort of open public space is characterized by the presence of greenery, the effect of water and sound, protection from rain and wind, sunlight during the winter, or shade during hot summer days. In accordance with this view, an open public space quality evaluation framework developed by Vukmirovic [30] covers the indicators divided into four clusters, namely vegetation and greenery, urban equipment, water features and urban morphology (see Figure 2). 


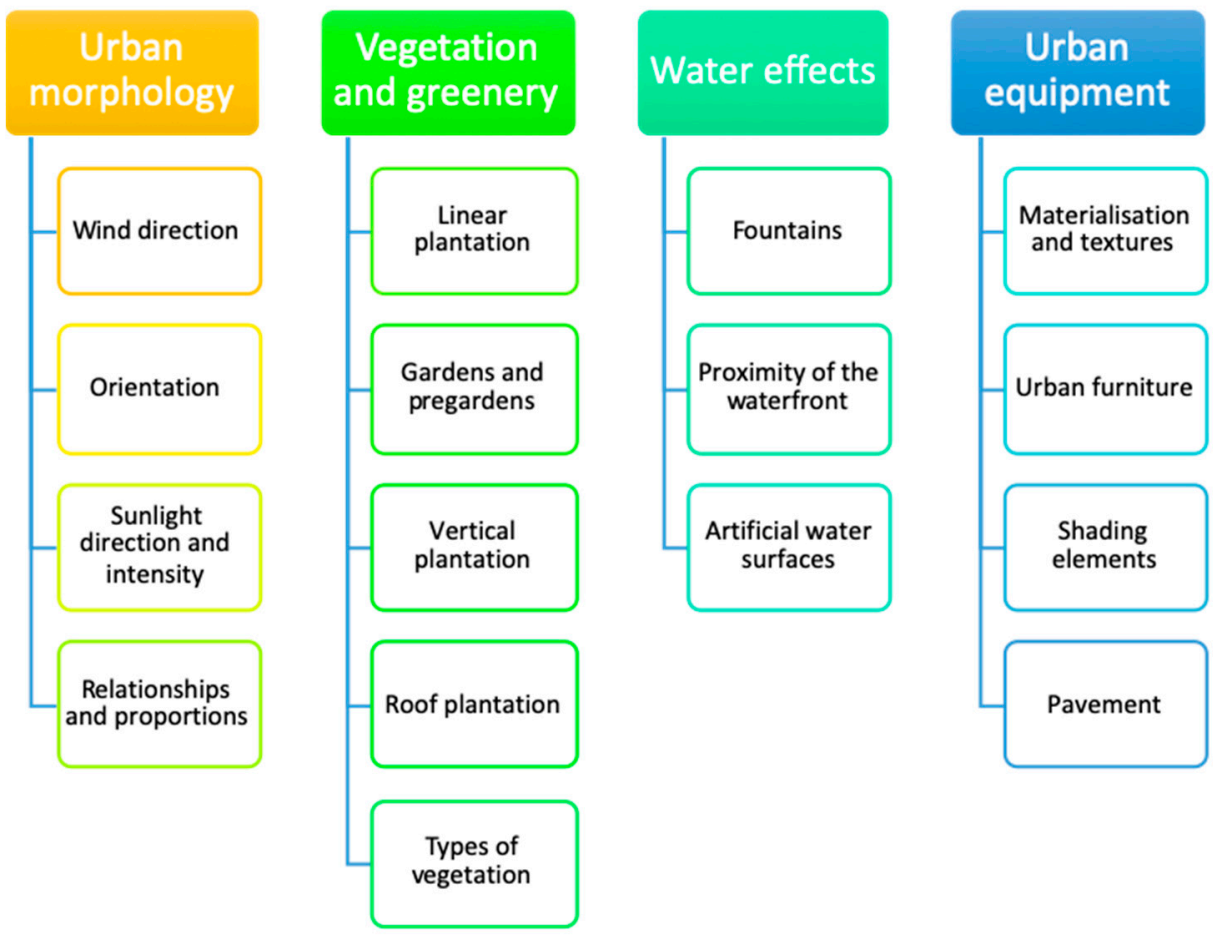

Figure 2. Open public space comfort clusters and indicators [20].

Urban morphology, or the spatial disposition of buildings can have the role of a barrier or a support between different ways of using open public space. The wind direction, position and prevalence of shadows or the length of sunny intervals depend on the relation and proportion of built structures, which also influence different microclimatic characters of the location. In addition to the improvement of microclimate characteristics, Vegetation and greenery can affect the psychological condition and cause a sense of comfort. Using greenery in terms of protection may contribute to comfort through protection from noise and pollution. This could depend on the approach based on the effects of specific vegetative configurations, such as linear, vertical, and surface configuration, or the configuration on roofs. A good selection of plant species, "which accounts for characteristics such as tree size, growth dimensions, crown density, biomass and foliation periods" [14] reduces the appearance of allergen (pollen) and promotes sensory experience-above all, the senses of sight, smell and hearing. Water effect is reflected through the presence of drinking fountains, fountains, misting systems and other water surfaces. In addition to aesthetic value, such elements could be used as landmarks or meeting points, suitable for socializing and leisure. Water elements could stimulate positive feelings thanks to calming water sounds. Furthermore, the presence of water is important because it could improve the climatic conditions of open public spaces, but "the wholesome effectiveness of evaporative cooling techniques is one that is contingent upon a variety of quantitative factors" [14]. Urban equipment and furniture could be considered an integral and inevitable element of open public spaces. Benches and other elements for sitting can be suitable places for socialisation and pleasant experiences if they are located at appropriate positions that provide the possibility of enjoying the views and conversation. Special attention in this domain is given to materialisation, pavement and shading elements. According to Santamouris et al. [36], the use of "cool materials," which contain both high solar reflectivity and emissivity, could lead to the decrease in surface/ambient temperatures and thus significantly improve the thermal comfort in public spaces. When viewing 'real' more reflective surfaces, with a lower emissivity, less radiation will be received by the thermometer than from a blackbody at the same temperature and so the surface will appear colder than it is, unless the thermometer reading is adjusted to take the material surface emissivity into account. Considering this, the improvement of comfort in open public space can be achieved by replacing conventional paving surfaces that emit higher surface temperatures. 
The comfort of a particular public space can be achieved by finding the adequate combination of the above-mentioned elements. Therefore, the open public space design process needs to be improved with a suitable analysis and conclusions in the early design stages in order to define an appropriate solution that could lead to expected results. This means that the general objective of the research is to define suggestions and recommendations for the "research on design", "research for design" and "research by design" [37] phases of the process.

\section{Materials and Methods}

This study used four methods which have been adjusted to the different territorial scopes that were analysed (wider location, the scope of particular open public space as an element of the wider network and segment of the open public space). These methods include an analysis of the coverage of the greenery in the wider territory using Geographic Information System (GIS) tools, a typological analysis of green infrastructure elements, an evaluation of open public space quality with a focus on the criteria of the comfort and simulation of microclimatic properties of the site using the ENVI Met digital microclimatic model. Therefore, the survey encompassed four phases, which included three different territorial frameworks that are observed by individual elements that affect the comfort of space-in the territory of the Lower Dorcol area located in the municipality of Stari Grad in Belgrade, Jevrejska Street, and the segment of Jevrejska Street on which the most radical design intervention was proposed (see Figure 3).

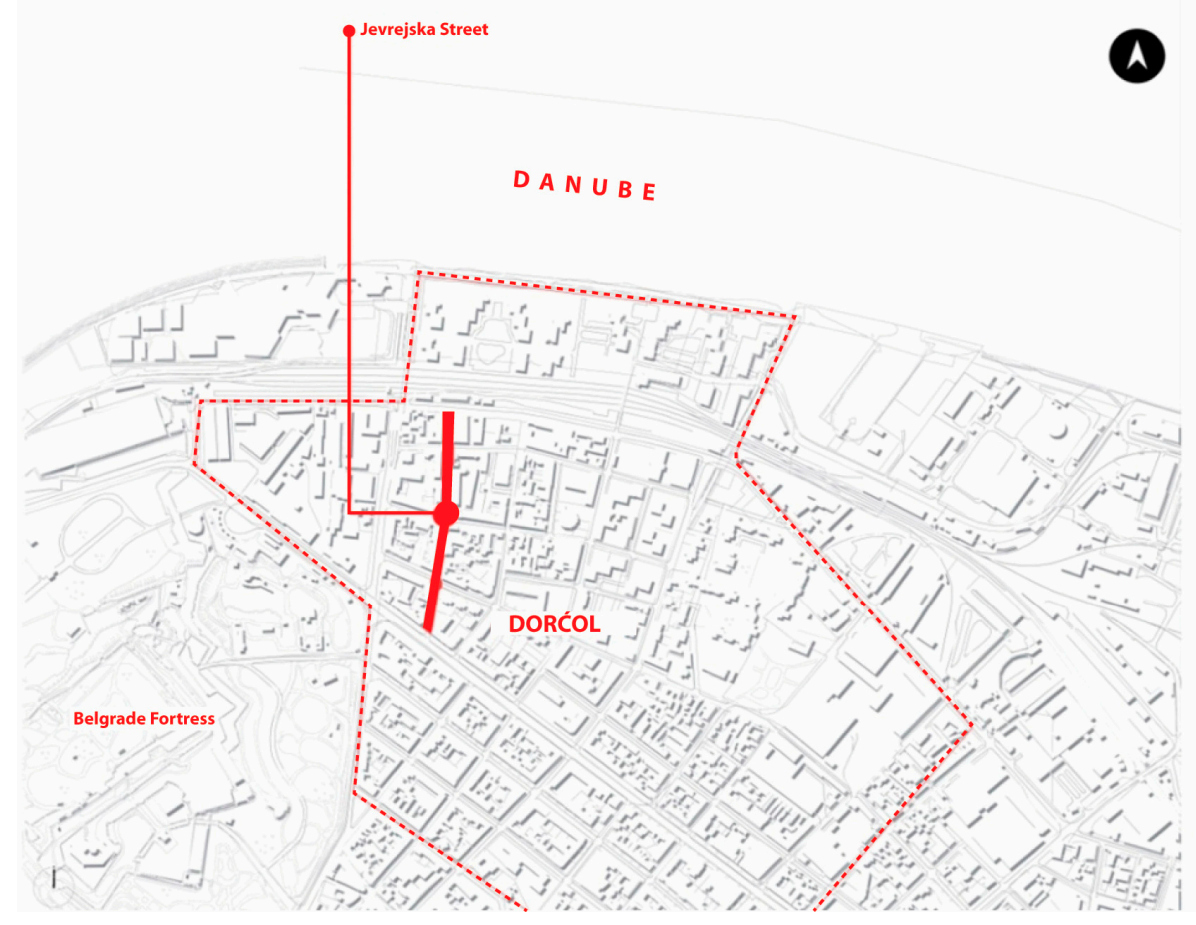

Figure 3. Research area and the position of Jevrejska Street.

The coverage of the greenery in the wider territory using GIS tools and typological analysis of green infrastructure elements is used for the study of the territory of Lower Dorcol, a densely built and populated area in one of the oldest parts of the city that connects the city centre with the Danube waterfront. Among other challenges of climate change, this area is characterized by the most pronounced heat waves in summer, due to the shortage of vegetation combined with the proliferation of tarmac and concrete surfaces and reduced air ventilation, as a characteristic of the central municipalities of Belgrade. The other reason is the need for the reconstruction of this area in order to meet new objectives such as direct connection with the Danube waterfront that is considered to be one of the 
strategic parts of the city that demands to become more attractive and liveable. At the next phase, being the subject of the open public space quality evaluation, with special focus put on comfort, Jevrejska Street was selected as one of the direct links between Cara Dusana Street (one of the most frequent streets of this area) and the Danube waterfront. The analysis covers approximately $4200 \mathrm{~m}^{2}$, i.e., the entire length of the street, which is approximately $370 \mathrm{~m}$. It was conducted at different periods between 25 September and 15 November 2018. The collected data were systematized and presented using graphics, maps and photographs of the specific situations that were evaluated using the framework defined by Bazik [22] and Vukmirovic [30].

The typological analysis of the elements of green infrastructure was made for the territory of Lower Dorcol with the aim of determining the existing state and defining a future solution. The development of this area includes providing semi-pedestrian streets with tree lines that will function as approach links to the large Line Park that will go along the Danube waterfront. Analysis of the green infrastructure network, i.e., the presence of its individual elements, relies on the typology of the elements of green infrastructure developed by the Green Surge Project (the green infrastructure elements included adequate classes retrieved from the Urban Atlas and Corine land cover database.) (2013). For the purpose of this analysis, the GIS of the green areas of Belgrade and the GEO-Serbia platform were consulted. The next methodological procedure includes analysis of the public space network and degree of the establishment of green infrastructure in the Lower Dorcol quartier using the GIS approach. In order to analyse the current state of the network of green and open spaces and to identify the potential for their connection, following the principles of green infrastructure, the first scale level of research is based on the analysis of information for the wider public space network-the Municipality of Stari Grad.

For spatial data, two datasets, produced as a part of the Copernicus Land Monitoring Service (CLMS), were used: The European Settlement Map (ESM) [38] and tree cover density (TCD) [39]. The European Settlement Map represents one of the latest updated versions about built up areas with an unprecedented detailed resolution that is $2.5 \mathrm{~m}$. The ESM distinguishes 13 classes, grouped into two macro domains: inside the built-up area and outside the built-up area [38]. According to NDVI values, the vegetation in built-up area (BU Area-Green NDVIx) and the vegetation out of the built-up area (NBU Area-Green NDVIx) are defined [38]. At the municipality level, the European Settlement Map distinguishes 7 thematic classes: water, railways, open spaces in non-built-up areas (NBU Open Space), vegetation in non-built-up areas (NBU Green NDVI), open spaces in built-up areas (BU Open Space), vegetation in built-up areas (BU Green NDVI) and built-up areas or buildings. Tree cover density can be defined as the "vertical projection of tree crowns to the horizontal earth's surface" and provides information on the proportional crown coverage per pixel [40]. Tree cover density range is from 0 to 100 per cent, where 0 means non-tree areas and 100 means maximum tree cover density, and a spatial resolution of $20 \mathrm{~m}$ determines which elements will be included in the tree-covered area.

The analysis of open public space quality covered the area of Jevrejska Street as a selected open public space within the wider network. It was conducted according to the method/framework defined by Bazik [22] and Vukmirovic [41] and includes the evaluation of safety, accessibility, comfort, legibility, attractiveness and liveability. For this analysis, special attention was paid to the comfort criteria and indicators divided into four clusters: vegetation and greenery, urban equipment, water features and urban morphology [41]. The purpose of the analysis was to provide more reliable information that will be used in further design of the best solution for the comfortable open public space.

The scenario design of the future transformation of Jevrejska Street was proposed based on the results of the open public space comfort analysis. The solution is further tested by using software for simulating microclimatic characteristics. Digital microclimatic software ENVI Met 4.0 was used in this part of the research in order to compare the actual and proposed state of the segment of Jevrejska Street, located between Dunavska and Mike Alasa Streets. The research the covered following analyses: solar influence, sun and shading exposure through real time, position of shadow in relation to physical structures, wind flow and speed analysis in relation to the complexity of the environment. 


\section{Results}

The results are presented following the overall structure of the research. Based on the Settlement Map that is used as spatial data and GIS analysis, it is notable that built-up areas or buildings are predominant as they cover 38.5 per cent of the municipality of Stari Grad (see Figure 4). The green spaces in the built-up areas that accommodate the surrounding buildings are evident as they cover 15.2 per cent of the area, but more apparent are the open spaces in built-up areas as they extend over 22.7 per cent of the researched area in total. Contrarily, the non-built-up green spaces are scattered alongside the riverbank and are the least prevailing as they spread on 0.2 per cent of the area and the non-built-up open spaces are also not significantly present as they only appear on 0.8 per cent.
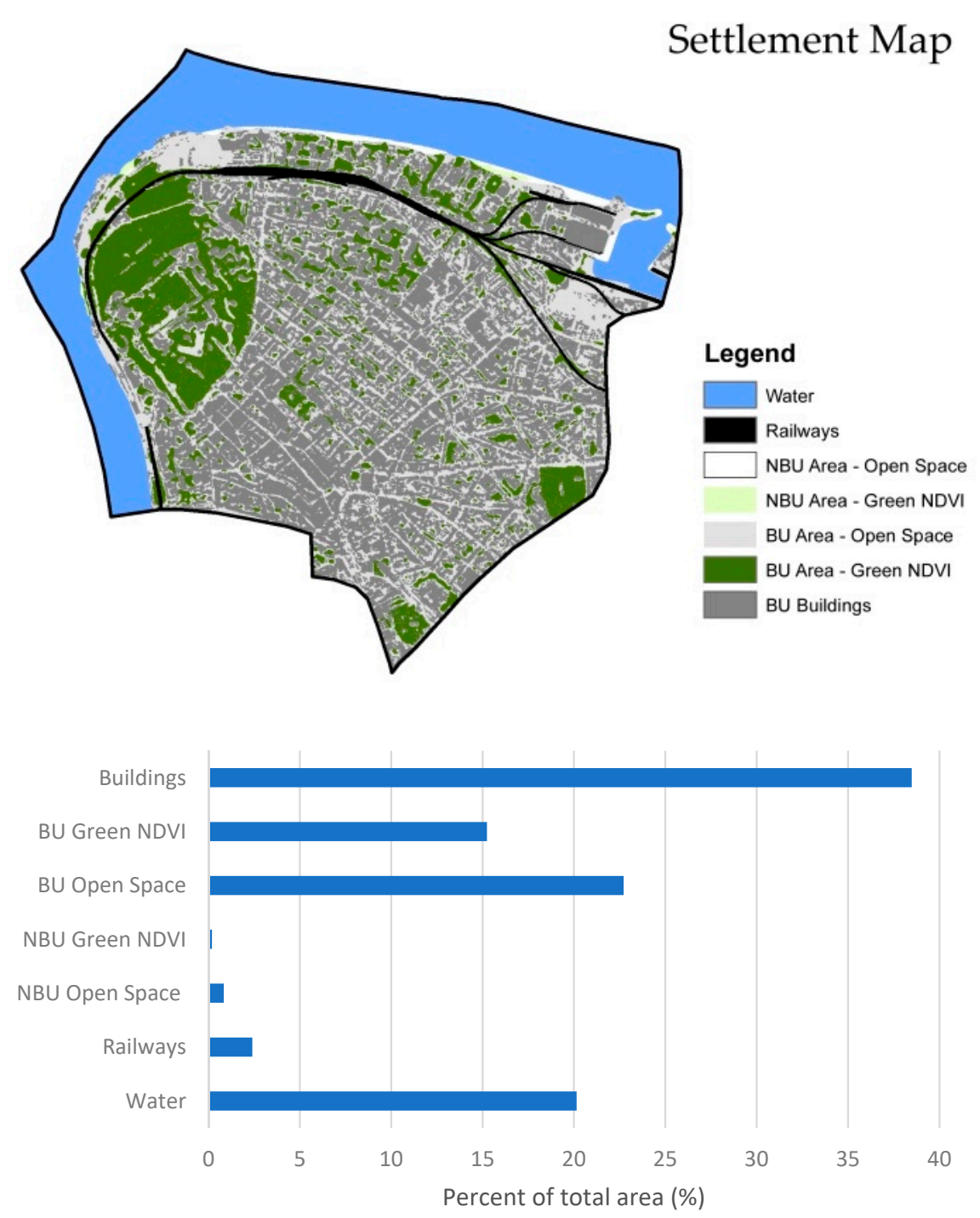

Figure 4. European Settlement Map—open and green spaces inside the built-up area and outside the built-up area.

As for the information gained from the tree cover density (see Figure 5) as per the spatial data map, it is noticeable that the tall urban vegetation in the municipality of Stari Grad is not sufficient, since 92.4 per cent of the area is categorized as the non-tree areas. The prevailing coverage of tree canopy is classified under 41-60 per cent of cover density and is distributed on 4.3 per cent of the area. All other categories of tree cover density are dispersed throughout the municipality and each covers less than 2 per cent of the area. 

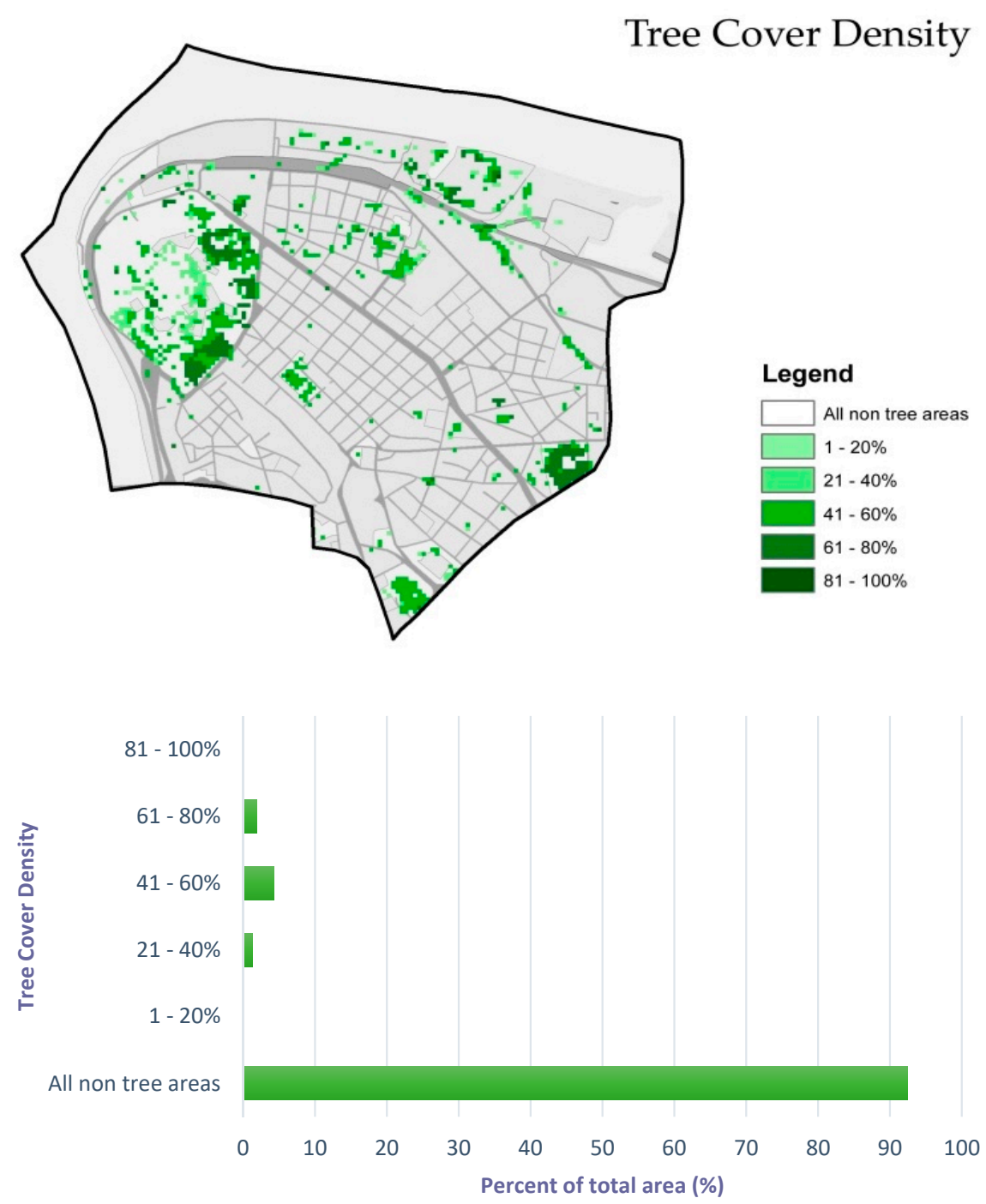

Figure 5. Tree cover density. Ratio between tree and non-tree areas.

The information and results that were attained from this GIS evaluation provided the guidelines for utilizing the potential of open spaces in built-up areas for connection of the intertwined elements as well as for applying the principles of green infrastructure.

In terms of a wider context, the heterogeneity of open urban spaces can be observed as a part of the green infrastructure of the city, which is further presented. The area of Lower Dorcol poses several macro elements of green infrastructure such as the city park (Kalemegdan), the area of Belgrade zoo, the greenery along the railway and the greenery along the Danube waterfront, while the mezzo elements include the local park, the greenery within the school facilities and tree alleys (see Figure 6). The most dominant element of the green infrastructure in the research area is the Kalemegdan Park with the Fortress and Belgrade Zoo. This park represents the connection with the element of urban block greenery of K-District through the corridor or the green space along the railway, which is not in function anymore. The block greenery at the coastline area is the second largest and important element. The observed macro elements have a good connection that has been developed through tree alleys. It was also observed that the continuity of the green infrastructure network is interrupted in certain places such as Jevrejska Street with a ratio of $100 \mathrm{~m}$. 


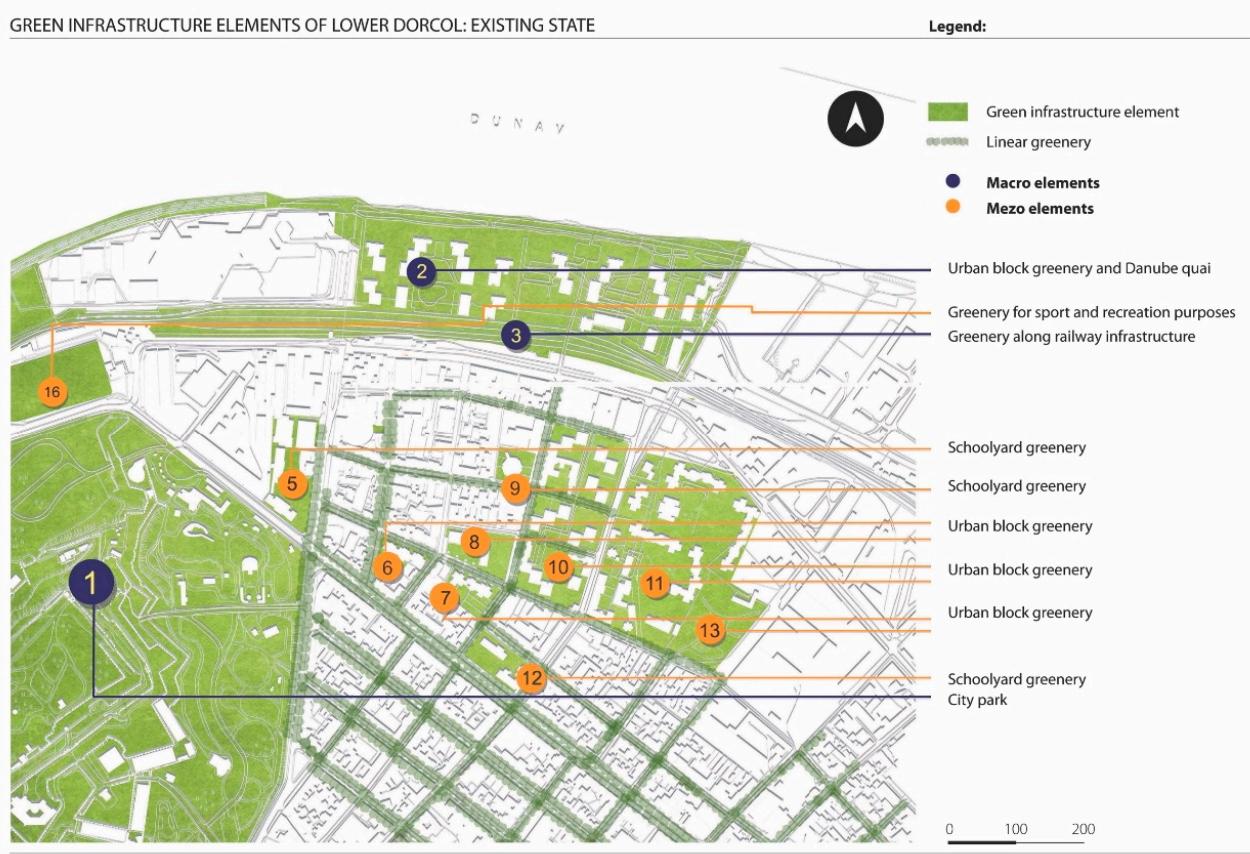

Figure 6. Typological classification of the elements of green infrastructure in Lower Dorcol. Existing state.

The scenario of the green infrastructure improvements envisions reconstruction of the "greenery along the railway infrastructure" in the form of the new linear park, which would achieve a strong connection between the Sava and the Danube waterfronts (see Figure 7).

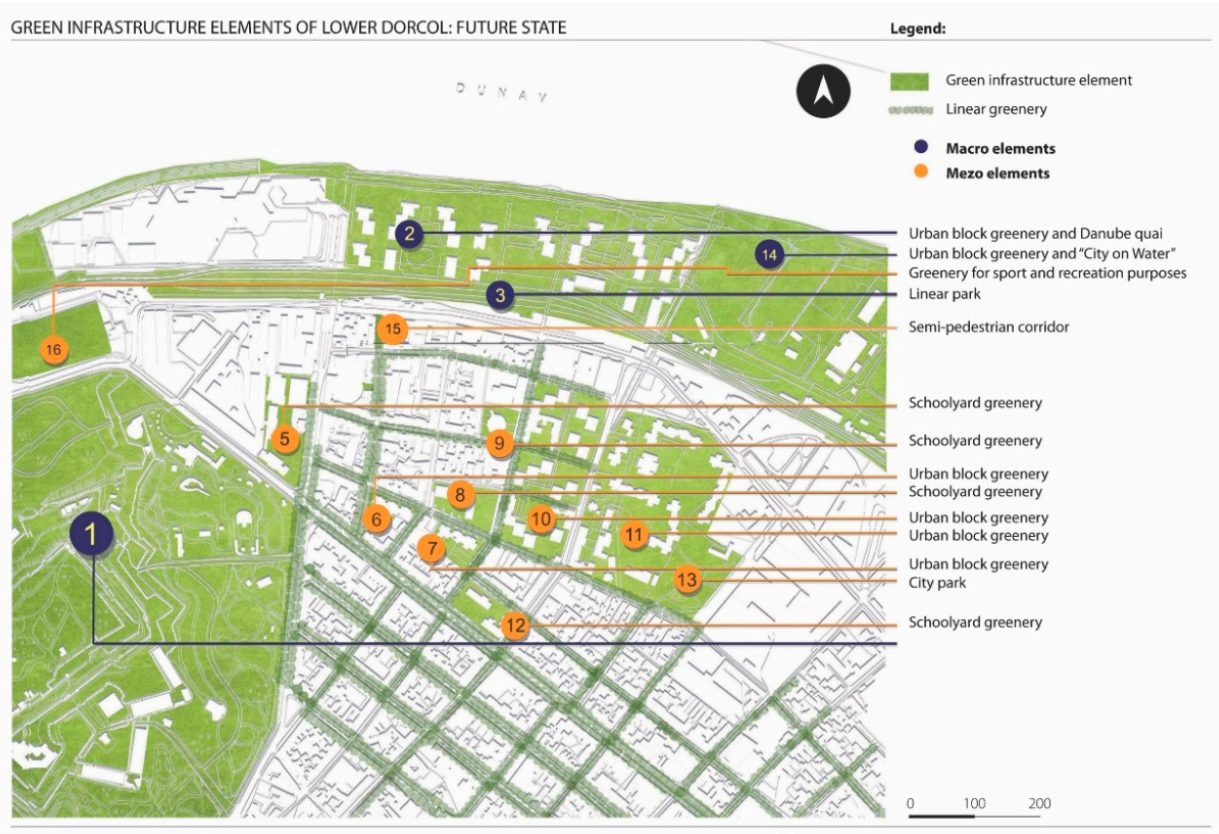

Figure 7. Typological classification of the elements of green infrastructure in Lower Dorcol. Future scenario.

This kind of intervention requires further access and a sort of "green" connection along the Jevrejska Street, with the intention to develop semi-pedestrian and pedestrian zones and with the introduction of a new tree alley with a length of $100 \mathrm{~m}$ in order to achieve physical connection between 
Cara Dusana Street and the Danube coastline. In addition, the future scenario also proposes block greenery in the Belgrade Port area.

The analysis of open public space comfort was made according to the indicators that include the position and orientation of building structures, direction of wind and sun, relation and proportion of buildings, presence and character of greenery, urban equipment, materialization of the surfaces and presence of water. Accordingly, the problem of no shadows is observed in the area of the crossing between Mike Alasa and Dunavska Streets (see Figure 8). Green alley is present in the part of the street defined by the crossings between Cara Dusana and Mike Alasa Streets. The rest of the street does not have trees or tree alleys. Water effects of any kind as well as the urban equipment are not present, while the street is paved with hard materials, mostly asphalt and concrete. Apart from this, Jevrejska Street could be described as a quiet street with moderate and slow traffic, which is also characterized by the absence of significant traffic pollution such as noise or air pollution. Considering the above-mentioned condition of the street, the overall comfort of Jevrejska Street is rated 2 (using the rating scale from 1 to 5 , where 1 is the worst and 5 is the best-rated condition).

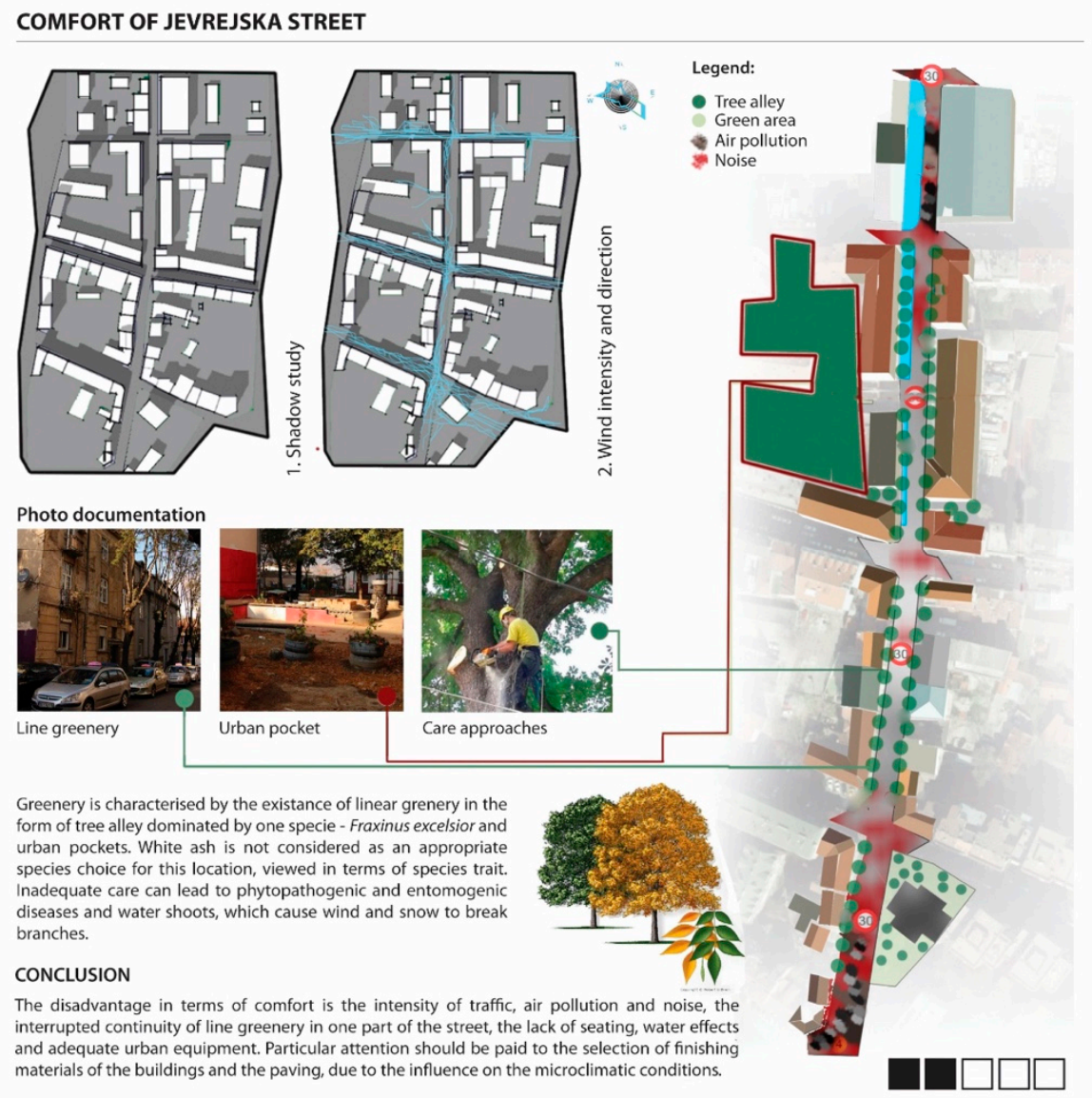

Figure 8. The comfort of Jevrejska Street in Belgrade.

Based on the presented results, the recommendations were defined in the form of the future design strategy [41], which contains the following improvements (Figure 9):

- Introduction of high greenery, which will provide a saturated ambient environment, which is considered as necessary, especially during hot summer days. The actual invasive sun lighting, as a consequence of the existing buildings' orientation, will be reduced by the setting of tall deciduous trees-the selection of which will depend on their biological and morphological characteristics. These species have to create a high-quality saturum, while during the winter, they would provide 
the ideal and necessary sunlight. In addition, the proposal includes the establishment of four grassy surfaces that will have water permeability.

- Installation of a water fountain, urban furniture (benches and litterbins) and urban equipment (lighting) - in order to create places for sitting, communicating and relaxing.

- Padding of the light, natural pavement. Light granite is proposed for the sidewalks with the expected intensive pedestrian traffic, while the other parts will be paved with stone cubes that could reduce the absorption of solar radiation and the impact of additional warming of space during the hot summer days. In addition, stone cubes can partially reduce the traffic speed, thereby further providing the sense of security and user comfort. The pavement will be installed in a way that leave openings in the ground to reduce the surfaces under waterproof curtains.

- Provision of levelling and curves-which would slow down the traffic. This would contribute to the overall comfort of the area and reduce traffic noise (Figure 10).
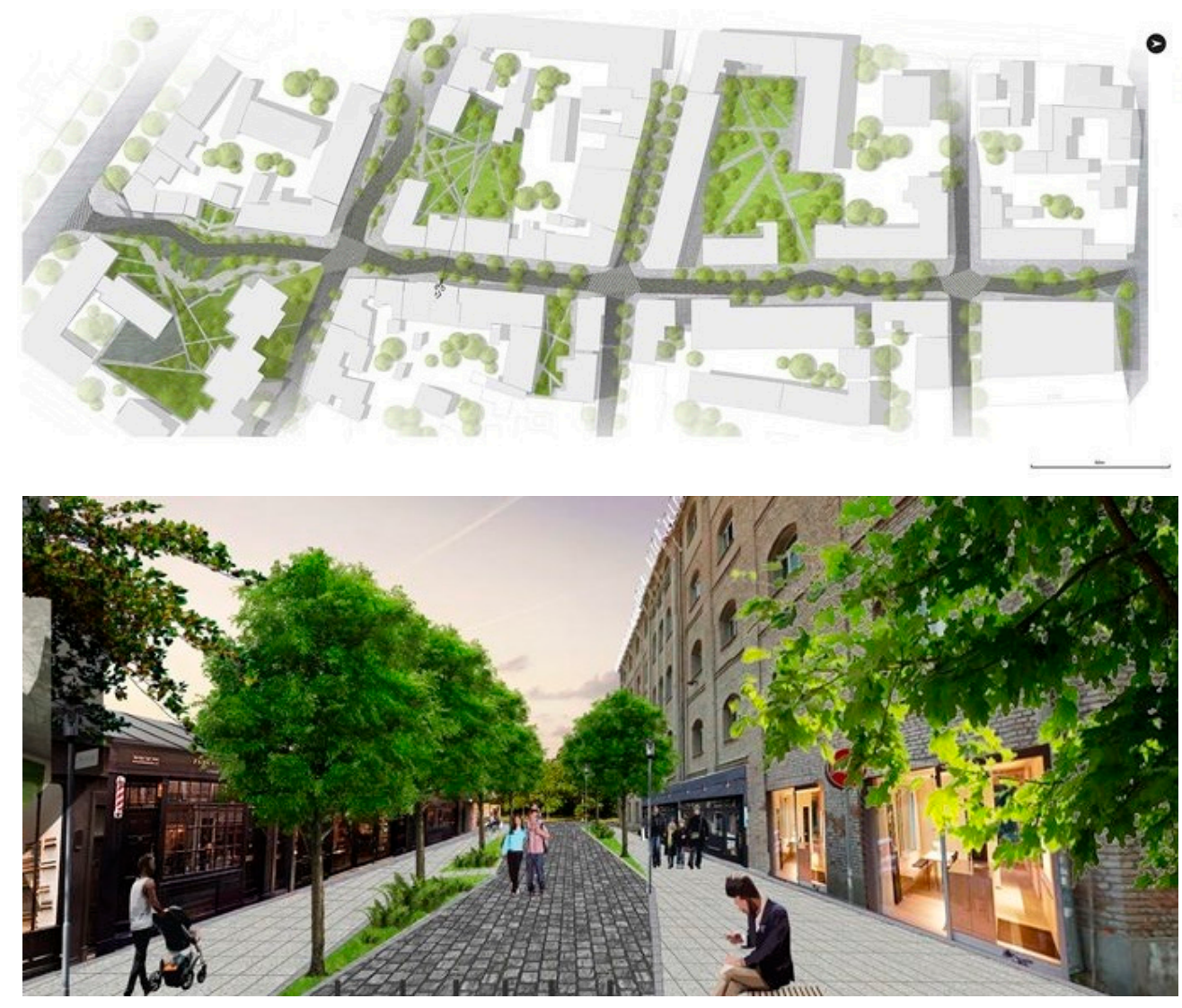

Figure 9. Design strategy of Jevrejska Street in Belgrade.

The presented design strategy and scenario were tested by using a selected segment of Jevrejska Street that was evaluated as the most unfavourable in relation to open public space comfort criteria and microclimate- the part between Mike Alasa and Dunavska Streets. The simulations were made using ENVI Met 4.0 software in order to present the situation for a typical for a summer day in Belgrade (using the maximum average temperature value on 21 June), while the analysis included the following measures of temperature, relative humidity, solar radiation, wind and shading. Apart from other indicators that could be analysed by using ENVI Met 4.0, the above-mentioned indicators were selected because they could be treated as a core group of indicators, the results of which should determine the continuation of the research and a more precise definition of the design proposal. 
The input data for the software were obtained from the Hydrometeorological Institute of the Republic of Serbia [42] including the extreme values, i.e., daily temperature of 40 degrees Celsius (13:00) and 23 degrees Celsius (06:00) and relative humidity from 61-62 per cent. For ventilation purposes, a strong wind is simulated with a speed of $6.9 \mathrm{~m} / \mathrm{s}$.

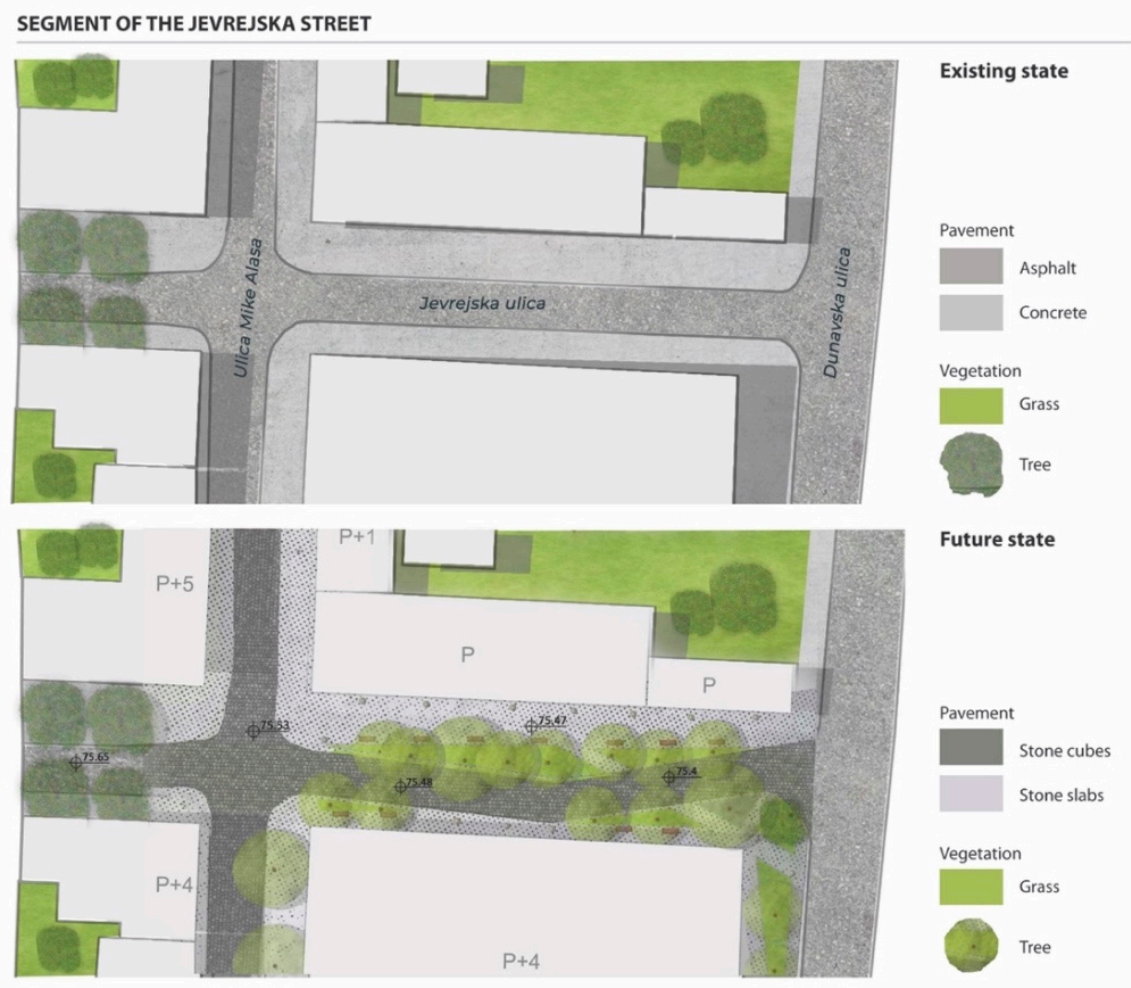

Figure 10. Existing and proposed state of the segment of Jevrejska Street.

By comparing the simulation diagrams between the existing and proposed state of the segment of Jevrejska Street, we can observe the difference in temperature of the area most covered with greenery. This lower temperature is the consequence of the solution proposing the high trees, introduction of the grass vegetation, replacement of the asphalt and concrete pavement with lighter stone slabs and cubes, which has a significant impact on the elevated air temperature. The use of the light grey granite slabs in paving sidewalks and cubes for driveway also contributes to decreased emissivity of the pavement surface and can improve the thermal comfort of the place.

Greenery can be seen as a perfect solution in terms of thermal comfort, while vegetation also reduces the appearance of reflections which is characterized by reflecting materials. Reflectivity is an optical property of material, which describes how much light is reflected from the material in relation to the amount of light incident on the material. Considering all the stated assumptions, the results have shown that the air temperature of the existing state of open public space amounts from 37 to 38 degrees Celsius. Consequently, it can be concluded that modified materialization and the use of vegetation and grassy areas can reduce the temperature by approximately 2 degrees Celsius during the warm summer days (see Figure 11). 


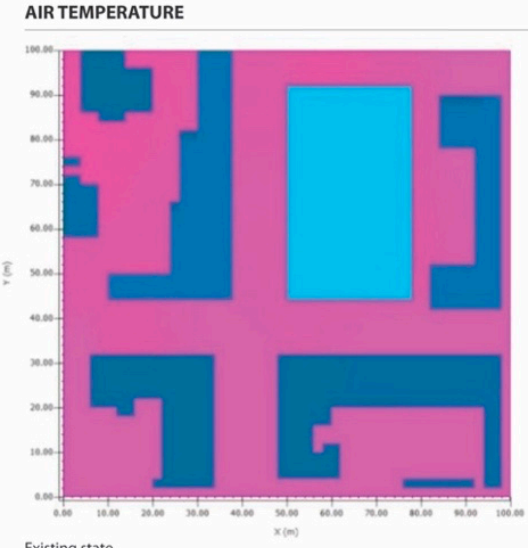

Existing state

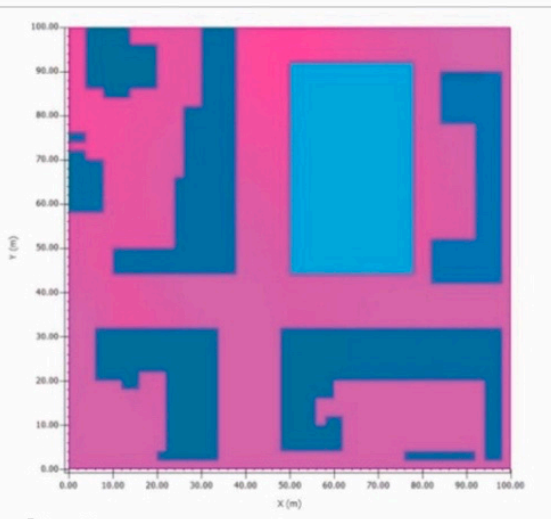

Future state

Figure 11. Air temperature simulation on existing and proposed state.

Relative humidity in the simulation of the existing state is approximately 50 per cent as opposed to the planned state where a drastic difference can be observed for the same period-between 55 per cent and 60 per cent. This can be interpreted in the way that greenery in open public space can contribute to the humidity by between 5 per cent and 10 per cent (see Figure 12). Even if the relative humidity does not act on thermal sensation [43], it could slightly influence acceptability of outdoor activity as well as individual feeling of comfort in a negative way.

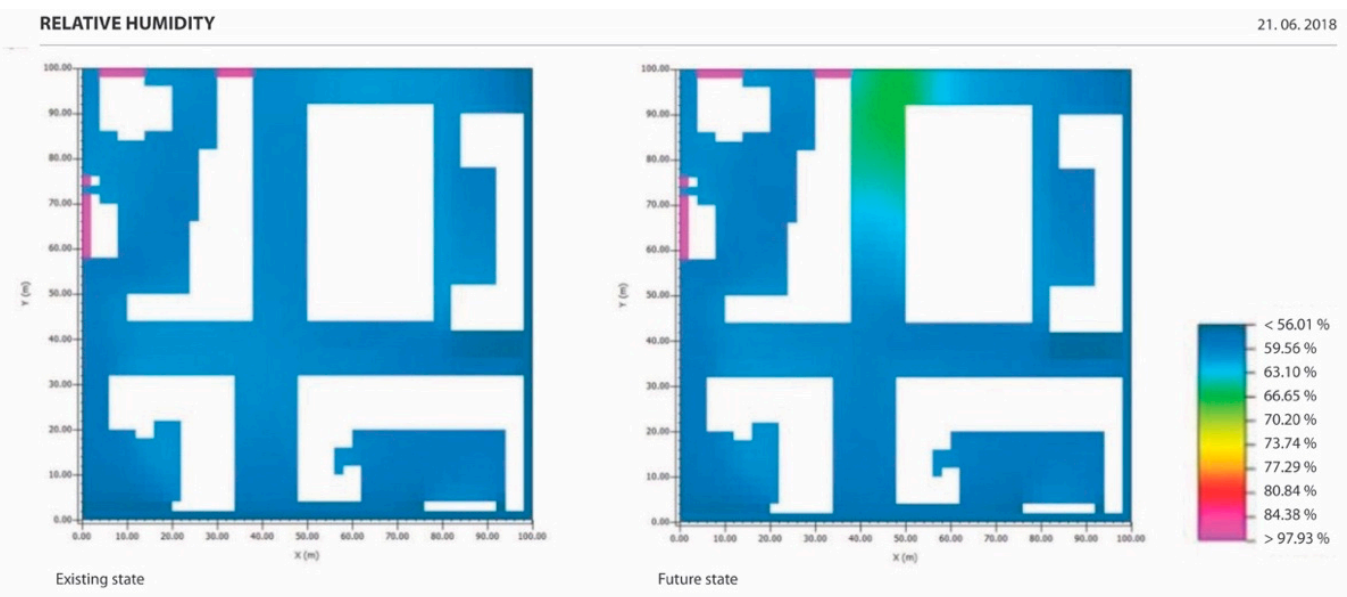

Figure 12. Relative humidity on existing and proposed state.

Solar radiation in case of the existing situation is very intensive, almost up to $223 \mathrm{~W} / \mathrm{m}^{2}$ during the noon period. In case of the design scenario, the tree alley can contribute to the extensive reduction of solar radiation during the noon period, which is even up to $161 \mathrm{~W} / \mathrm{m}^{2}$ (see Figure 13). This microclimatic characteristic is of great importance, because it can determine the comfort of particular public space, especially during the hottest part of the day. 

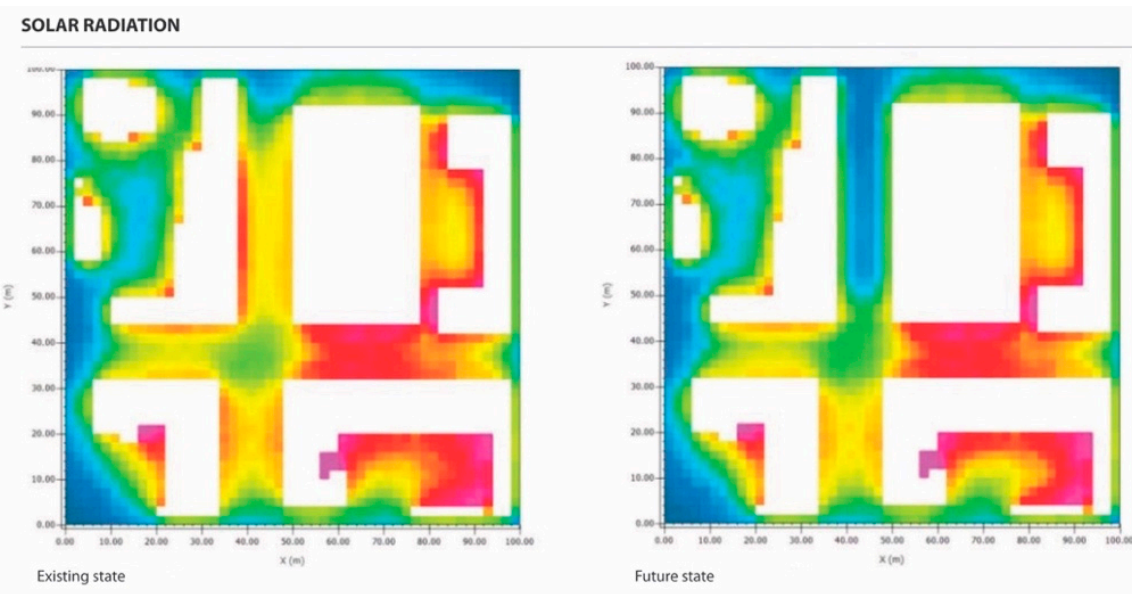

Figure 13. Solar radiation on existing and proposed state.

In addition to the above, solar radiation is used for the purpose of the core observation of the changes arising from the initial design proposal. Accordingly, further design proposal development, which includes precise selection and finishing of stone, should include more indicators such as surface emissivity and friction coefficients that would give us a more detailed insight.

The simulation of winds with a speed of $6.9 \mathrm{~m} / \mathrm{s}$ showed winds of $6.18 \mathrm{~m} / \mathrm{s}$ to the north direction, depending on the influence of the surrounding buildings. According to the Beaufort scale, this wind is rated 4 , as a moderate breeze. In the planned scenario, the introduction of the tree alley does not alter the wind direction, but partially slows down the wind by a total of $0.72 \mathrm{~m} / \mathrm{s}$. Winds which are faster than $9.75 \mathrm{~m} / \mathrm{s}$ (rated 5 to 6 , fresh to strong breeze) are observed at some points within the inner block area. These areas are much more pronounced in the future than in the current state (see Figure 14).
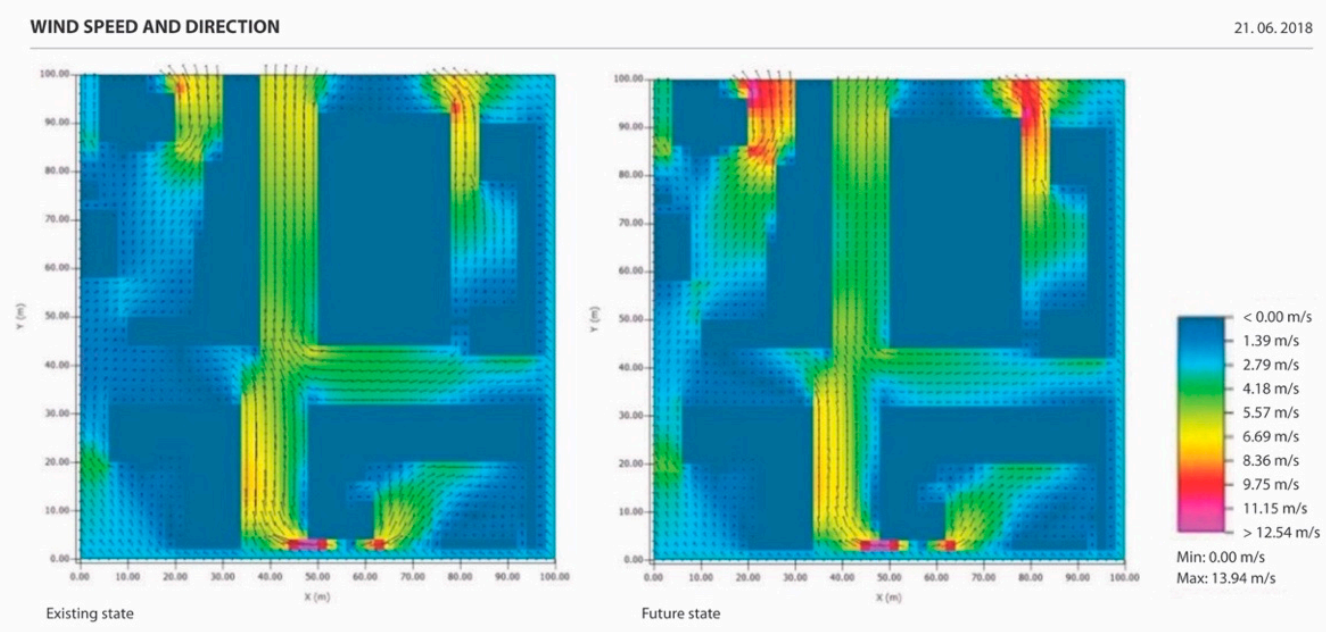

Figure 14. Wind speed and direction under the trees on existing and proposed state.

Exposure to sun and position of shade, by comparing the existing and planned state, clearly reveals the existence of shadows during the hottest part of the day (see Figure 15). Using the leafy vegetation in open public space design proposals improves the microclimatic characteristics of the space. The air temperature in the shade is lowered and suitable for staying outdoors, while during the winter, after the fall of leaves, the required sun exposure is enabled. 

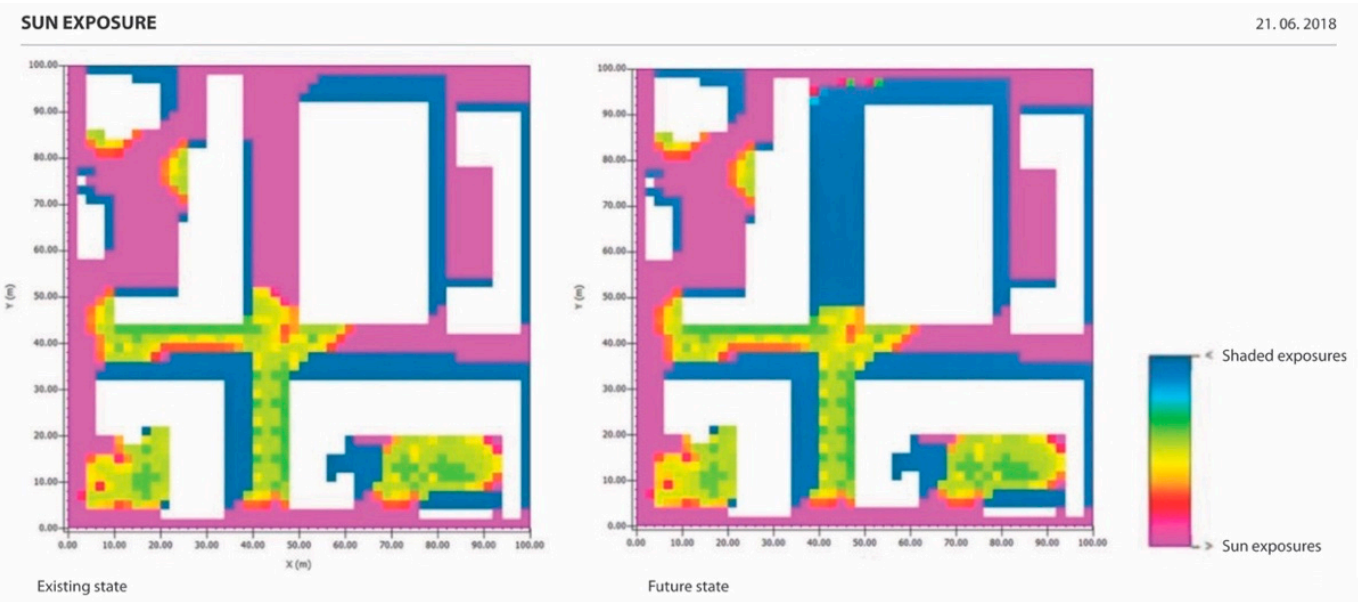

Figure 15. Sun exposure and shade position on existing and proposed state.

These results show the positive impact of urban greenery on the microclimate of the open public space (at a small scale), or on the climate at a higher scale, if it is observed as an element of green infrastructure. In addition to the impact of greenery, the influence of horizontal surface materialization has been examined as well. The solar radiation in urban areas is particularly accumulated by dark, unreflective surfaces, such as asphalt, that release heat to the environment. Due to the above, the design scenario of Jevrejska Street includes the replacement of concrete and asphalt and the use of natural materials-light granite and stone cubes. Considering this, it can be said that greenery and surface materials are of the greatest importance in a responsible design of open public spaces with the aim to make of comfort, as well as being suitable for future challenges of climate change.

\section{Discussion}

Humans are social beings who need spaces where they can gather and where events occur, and such a scenario is possible if people linger in such a place. There are many reasons for why a person will spend time outdoors. However, if we are talking about users as a group, we can certainly claim that they will spend time in a public space if they feel safe and comfortable.

The comfort of open public spaces cannot be imagined without good microclimate conditions and protection against noise and pollution. Accordingly, good open public spaces can be considered as "fortifications" that defend their users from noise, polluted air, negative aspects of the microclimate, and as "providers" of positive sensory experiences. Furthermore, urban greenery contributes to the city environment as an individual element in a small area, as well as on the city level, viewed as an element of the green infrastructure network.

In the period characterised by Anthropocene and challenged by climate change, the responsible design must be more than the pure beautification of space and harmonisation of colours of different materials and contemporary forms. It needs to be clever and careful, looking at urban environment as a part of a broader natural environment. Accordingly, the inclusion of microclimate digital models as an integral part of the open public space design process offers the possibility of testing and simulating design solutions, from the aspect of climate characteristics of space. It also offers a simple and accurate design of the thermal comfort of open public space. The simulation of climate conditions on the segment of Jevrejska Street in Belgrade has shown that a simple introduction of a tree alley and natural paving materials can make adequate thermal settings for staying outdoors.

The research of "for design", "on design" and "by design" results, presented in this paper, could serve as a direction for the next research phase- "on design", that will include testing of different materials-types of stone, their textures and sizes, as well as selection of deciduous tree sessions. These species need to have the ability to withstand extreme weather conditions, to be locally sourced and easily maintained and nurtured. According to the above, new indicators and tools will be 
used for the next "by design" phase, such as surface reflection, emissivity or friction coefficients for pavement materials [44-47]; research of the subjective comfort assessment using simulation tools for physiologically equivalent temperature (PET) and the standard effective temperature (SET) [48-50], combined with the results obtained from the surveys of the users of Jevrejska Street; and research in the domain of landscape horticulture and engineering that will focus on the issues of species selection and their characteristics and behaviour in extreme weather circumstances [51]. Also, the research should include other periods during the year-winter, spring, summer and autumn, and extreme summer and winter events.

The improvement of open public space comfort should not be an isolated goal but should be seen in relation to other criteria that define the quality of open public space. Accordingly, the prerequisite of a good open public space and each of the criteria is a part of the hierarchy that requires detailed comprehensive analysis. In addition, this criterion is covered by a very important issue on environmental protection and the reduction of climate change effects. As Stephen Hawking said, we "must remember that science and technology are changing our world dramatically, so it's important to ensure that these changes are heading in the right directions" [7], especially if we know that "there is no Planet B" [3].

Author Contributions: Conceptualization, M.V.; Data curation, D.S.; Formal analysis, S.G. and D.S.; Methodology, M.V. and S.G.; Supervision, M.V.; Validation, M.V.; Visualization, S.G., D.S. and M.V.; Writing—original draft, M.V.

Funding: This research received no external funding.

Acknowledgments: A part of this research was carried out during the second part of 2018 within the elective Master Course Open Public Space Design at the University of Belgrade-Faculty of Forestry, chaired by Milena Vukmirović, PhD, while this paper was carried out within two national scientific projects funded by the Ministry of Education, Science and Technology of the Republic of Serbia: No. 177009 Modernization of the Western Balkans and No. 43007 Studying climate change and its influence upon the environment: impacts, adaptation and mitigation.

Conflicts of Interest: The authors declare no conflict of interest.

\section{References}

1. Gehl, J. Cities for People; Island Press: Copenhagen, Denmark, 2010.

2. Edwards, L.E. What Is the Anthropocene? 30 November 2015. Available online: https://eos.org/opinions/w hat-is-the-anthropocene (accessed on 12 September 2019).

3. Crutzen, P.J.; Stoermer, E.F. The Anthropocene. Glob. Chang. Newsl. 2000, 41, 17-18.

4. Berners-Lee, M. There Is No Planet B: A Handbook for the Make or Break Years; Cambridge University Press: Cambridge, NY, USA, 2019.

5. Ellis, E.C. Anthropocene: A very Short Introduction; Oxford University Press: Oxford, UK, 2018.

6. Ruddiman, W.; Ellis, E.; Kaplan, J.; Fuller, D.Q. Defining the epoch we live in. Science 2015, 38, 348. [CrossRef] [PubMed]

7. Hawking, S. Interviewee. Lecture 2: Black Holes Ain't as Black as They Are Painted, 2 February 2016.

8. EEA. The European Environment State and Outlook 2015. In Assessment of Global Megatrends; European Environment Agency: Copenhagen, Denmark, 2015.

9. CROW. Adapting Public Space to Climate Change-Municipal Councils Set to Work on Climate Adaptation. July 2015. Available online: http://edepot.wur.nl/307492 (accessed on 12 August 2019).

10. UN Habitat. Climate Change. 10 July 2017. Available online: http://unhabitat.org/urban-themes/climate-cha nge/ (accessed on 12 September 2019).

11. CIFF. Cities in the Frontline. Planning for Low-Carbon Future. 24 March 2017. Available online: https: //ciff.org/impact/cities-frontline/ (accessed on 12 September 2019).

12. OECD. Cities and Climate Change; OECD Publishing: Paris, France, 2010.

13. Djukic, A.; Vukmirovic, M.; Stankovic, S. Principles of climate sensitive urban design analysis in identification of suitable urban design proposals. Case study: Central zone of Leskovac competition. Energy Build. 2016, 115, 23-35. [CrossRef]

14. Nouri, S.A.; Costa, J.P. Placemaking and climate change adaptation: New qualitative and quantitative considerations for the Place Diagram. J. Urban. 2017, 10, 356-382. 
15. Djekic, J.; Djukic, A.; Vukmirovic, M.; Djekic, P. Thermal comfort of pedestrian spaces and the influence of pavement materials on warming up during summer. Energy Build. 2018, 159, 474-485. [CrossRef]

16. Ovstedal, L.; Ryeng, E.O. Understanding pedestrian Comfort in European Cities: How to Improve Walking Conditions? In Proceedings of the European Transport Conference, Cambridge, UK, 9-11 September 2002; Association of European Transport: London, UK, 2002.

17. Hajep, M.; Reijndorp, A. New Public Domain: Analysis and Strategy; NAi Publishers: Rotterdam, The Netherlands, 2001.

18. UN-Habitat. Global Public Spaces Toolkit Global Principles to Local Policies and Practice. 2015. Available online: http://unhabitat.org/wp-content/uploads/2015/10/Globalpercent20Publicpercent20Spacepercent2 0Toolkit.pdf (accessed on 13 September 2019).

19. UNESCO. Inclusion Through Access to Public Space. 2017. Available online: http: //www.unesco.org/new/en/social-and-human-sciences/themes/urban-development/migrants-inclus ion-in-cities/good-practices/inclusion-through-access-to-public-space/ (accessed on 13 September 2019).

20. Kristie, D. Public Spaces: A Key Tool to Achieve the Sustainable Development Goals. 22 July 2016. Available online: https://ncdalliance.org/news-events/blog/public-spaces-a-key-tool-to-achieve-the-sustainable-dev elopment-goals (accessed on 12 September 2019).

21. Vukmirovic, M. Importance and Role of Pedestrian Spaces in Generating Competitive Identity of Cities. Ph.D. Thesis, University of Belgrade-Faculty of Architecture, Belgrade, Serbia, 2013.

22. Bazik, D. Relacijski Prostor Grada: Projekat: Tekst: Realizacija; Arhitektonski fakultet Univerziteta: Belgrad, Serbia, 2008.

23. Whyte, W.H. The Social Life of Small Urban Spaces; Project for Public Spaces Inc.: New York, NY, USA, 2001.

24. Golany, G.S. Urban Design Morphology and Thermal Perfomance. Atmos. Environ. 1996, 30, 455-465. [CrossRef]

25. Sanaieian, H.; Tenpierik, M.; van den Linden, K.; Seraj, F.M.; Shermani, S.M.M. Review of the Impact of Urban Block Form on Thermal Perfomance, Solar Access and Ventilation. Renew. Sustain. Energy Rev. 2014, 38, 551-560. [CrossRef]

26. Jamei, E.; Rajagopalan, P. Urban Growth and Pedestrian Thermal Comfort. In ASA2015: Living and Learning: Research for a Better Built Environment: Proceedings of the 49th International Conference of the Architectural Science Association; University of Melbourne: Melbourne, Australian, 2015.

27. Kim, Y.H.; Baik, J.J. Spatial and Temporal Structure of the Urban. J. Appl. Meteorol. 2005, 5, 591-605. [CrossRef]

28. Santamouris, M. (Ed.) Energy and Climate in the Urban Built Environment; Routledge: London, UK, 2013.

29. Mendoza, J.M.F.; Oliver-Sola, J.; Gabarell, X.; Rieradevall, J.; Josa, A. Planning Strategies for Promoting Environmentally Suitable Pedestrain Environment. Transp. Res. Part D 2012, 24, 442-450. [CrossRef]

30. Vukmirovic, M.; Djukic, A.; Antonic, B. Place Networks. In Experience the City on Foot; University of Belgrade-Faculty of Architecture: Belgrade, Serbia, 2018.

31. Gehl, J. Life between Buildings; Island Press: Copenhagen, Denmark, 1987.

32. Francis, M. Urban Open Space: Designing for User Needs; Island Press: London, UK, 2003.

33. Boer, F.; Salinas, E.M.; Kalnpure, A.; Aquisito, L.; Wissing, A.; Stevens, T.; Lloyd, S.; van Peijpe, D. Good Green Is Golden; De Urbanisten: Rotterdam, The Netherlands, 2016.

34. Vasiljevic, N.; Radic, B.; Gavrilovic, S.; Sljukic, B.; Medarevic, M.; Ristic, R. The concept of green infrastructure and urban landscape planning: A challenge for urban forestry planning in Belgrade, Serbia. iFor. Biogeosci. For. 2018, 11, 491-498. [CrossRef]

35. Loufai, B.; Abdou, S. Effet de L'ombrage Sur le Confort Thermique et Visuel Dans Les Espaces Extérieurs; Revue Nature \& Technologie: Constantine, Algeria, 2012.

36. Santamouris, M.; Gaitani, N.; Spanou, A.; Salirai, M.; Giannopoulou, K.; Vasilakopoulou, K.; Kardomateas, T. Using Cool Paving Materials to Improve Microclimate of Urban Areas-Design Realization and Results of the Flisvos Project. Build. Environ. 2012, 53, 128-136. [CrossRef]

37. Lenzhoölzer, S. Designing Atmospheres Research and Design for Thermal Comfort in Dutch Urban Squares. Ph.D. Thesis, Wageningen University, Wageningen, The Netherland, 2010.

38. JRC. European Settlement Map. 2017. Available online: https:/land.copernicus.eu/pan-european/GHSL/eur opean-settlement-map/esm-2012-release-2017-urban-green (accessed on 1 September 2019). 
39. EEA. Tree Cover Density. 2015. Available online: https:/land.copernicus.eu/pan-european/high-resolutionlayers/forests/tree-cover-density/status-maps/2015 (accessed on 1 September 2019).

40. EEA. Copernicus Land Monitoring Service-High Resolution Layer Forest: Product Specifications Document; European Environmental Agency: Copenhagen, Denmark, 2018.

41. Vukmirovic, M. Comfort of Open Public Space; University of Belgrade-Faculty of Forestry: Belgrade, Serbia, 2018.

42. Hydrometeorological Institute of the Republic of Serbia. Available online: http://www.hidmet.gov.rs (accessed on 10 September 2018).

43. Jing, S.; Li, B.; Tan, M.; Liu, H. Impact of Relative Humidity on Thermal Comfort in a Warm Environment. Indoor Built Environ. 2013, 22, 598-607. [CrossRef]

44. Santamouris, M. Cool pavements to mitigate urban heat islands. In Urban Climate Mitigation Techniques; Santamouris, M., Kolokotsa, D., Eds.; Routledge: London, UK, 2016.

45. Tran, N.; Powell, B.; Marks, H.; West, R.; Kvasnak, A. Strategies for Design and Construction of High-Reflectance Asphalt Pavements. Transp. Res. Rec. 2009, 2098, 124-130. [CrossRef]

46. Chen, J.; Wang, H.; Xie, P. Pavement temperature prediction: Theoretical models and critical affecting factors. Appl. Therm. Eng. 2019, 158. [CrossRef]

47. Wu, H.; Sun, B.; Li, Z.; Yu, J. Characterizing thermal behaviors of various pavement materials and their thermal impacts on ambient environment. J. Clean. Prod. 2018, 172, 1358-1367. [CrossRef]

48. Staiger, H.; Laschewski, G.; Grätz, A. The perceived temperature-A versatile index for the assessment of the human thermal environment. Part A: Scientific basics. Int. J. Biometeorol. 2011, 56, 165-176. [CrossRef] [PubMed]

49. Chen, Y.C.; Matzarakis, A. Modified physiologically equivalent temperature-Basics and applications for western European climate. Int. J. Biometeorol. 2017. [CrossRef]

50. Staiger, H.; Laschewski, G.; Matzarakis, A. Selection of Appropriate Thermal Indices for Applications in Human Biometeorological Studies. Atmosphere 2019, 10, 18. [CrossRef]

51. Teskey, R.; Wertin, T.; Bauweraerts, I.; Ameye, M.; McGuire, M.A.; Steppe, K. Responses of tree species to heat waves and extreme heat events. Plant Cell Environ. 2015, 38, 1699-1712. [CrossRef] [PubMed] 